\title{
Food Insecurity in Vulnerable Populations: Coping with Food Price Shocks in Afghanistan
}

\author{
Anna D'Souza and Dean Jolliffe
}

\begin{abstract}
Based on data from Afghanistan collected prior to and during the 2007-2008 food price crisis, this paper illustrates that caloric intake is an ineffectual indicator for monitoring the onset of food insecurity. Unconditional Quantile Regression estimates indicate that the most vulnerable of households, which cannot afford to make substantial cuts to calories, exhibit no decline in caloric intake in response to increasing wheat prices. In contrast, households with high-calorie diets experience large declines. The estimates also reveal declines in dietary diversity across the entire distribution of households. The most vulnerable households may be sacrificing diet quality to maintain calories, with the potential for serious and long-term health consequences.
\end{abstract}

Key words: Afghanistan, food price shock, food security, nutrition, poverty, wheat, unconditional quantile regression.

JEL codes: D12, I3.

As 2015 nears and the international development community evaluates the progress made on the Millennium Development Goals (MDG), food security and nutrition are emerging as critical development priorities. This is partly because most countries are lagging behind on efforts to meet the two nutrition-related MDG goals of child mortality and maternal mortality (World Bank and International Monetary Fund 2012), and partly because elevated global food prices have led to an erosion of purchasing

\footnotetext{
Anna D'Souza is a research economist at the Economic Research Service, U.S. Department of Agriculture. Dean Jolliffe is a senior economist at the World Bank, and also holds affiliations with the Institute for the Study of Labor in Bonn, Germany, and the National Poverty Center at the Ford School of Public Policy, University of Michigan. The authors are grateful to the Central Statistics Organization, Government of Afghanistan (GoA), for granting access to the data for poverty research. Findings from this analysis provide background information for the World Bank's poverty assessment for Afghanistan, and have informed the GoA Ministry of Economy. The authors wish to thank for comments the editor, Ed Taylor, and two anonymous reviewers, Maurice Landes, Ismail Rahimi, Hans G.P. Jansen, seminar participants at the World Bank-Kabul office, and conference participants at the AAEA 2011 annual meeting. Jolliffe gratefully acknowledges support from Australian Aid and the World Bank's Research Support Budget. The views expressed here are those of the authors and may not be attributed to the Economic Research Service, the U.S. Department of Agriculture, the World Bank, the Institute for the Study of Labor, or the National Poverty Center. Correspondence may be sent to: anna.dsouza@gmail.com.
}

power for households throughout the developing world. During the 2007-2008 food price crisis, many households were forced to reduce both the quantity and quality of food they consumed (International Fund for Agricultural Development 2008; Sanogo 2009) and approximately 105 million people were pushed into or kept in poverty (World Bank and International Monetary Fund 2012).

With over two billion people estimated to be suffering from mineral and vitamin deficiencies worldwide (Micronutrient Initiative and UNICEF 2009), sharp increases in food prices can have deleterious effects on households living below or near subsistence levels. Even short bouts of poor nutrition can have long-term repercussions, particularly for vulnerable populations and those with high nutritional needs like children, lactating and pregnant women, and the elderly (UNICEF 2009). While well-recognized by nutritionists, dietary quality has been largely overlooked by economists. Traditionally economic analyses of hunger have focused on calories alone, but "hidden hunger" (a term that refers to micronutrient deficiencies) can have serious implications for long-term human capital formation.

In this article, we use the case of Afghanistan during the 2007-2008 food price 
crisis to illustrate the impact of staple food (wheat flour) price increases on the food security of vulnerable households. ${ }^{1}$ During the examined period and due to both international and domestic factors, the price of wheat flour doubled. We examine the impact on the quantity (caloric intake) and quality (dietary diversity) of food consumed, along with other indicators of diet quality. In order to focus on vulnerable households, we use the Unconditional Quantile Regression (UQR) estimator, recently proposed by Firpo, Fortin, and Lemieux (2009), to identify price effects for households located at specific points on the unconditional distributions (such as the $20^{\text {th }}$ or $80^{\text {th }}$ quantiles) of the food security indicators. By contrasting effects at several points on the distribution, this article aims to answer whether responses to prices shocks differ in informative ways.

Moving beyond the price responses for the average household can help inform policy makers of how society's most vulnerable are affected by price increases. Such information is particularly salient in a country like Afghanistan, where decades of war, political instability, and recurring droughts have led to a precarious state of food insecurity and poverty. ${ }^{2}$ For the purposes of examining food security, or indeed any measure where the policy focus is on a particular portion of the distribution (such as the lower tail), it is beneficial to move beyond an estimator like ordinary least squares (OLS), which constrains the behavioral response of households to being constant over the entire distribution. Therefore, while OLS provides a good point of departure for policy analysis, if households at different points of the distribution are impacted differently by price shocks, OLS will mask these differences. To address this concern, an examination of more disaggregated behavioral responses is merited. Because development policy often focuses on people living at or below subsistence levels, it is important to allow for the possibility that the behavioral responses of vulnerable households differ in ways that are policy-relevant.

Evidence indicates that Afghan households across the distribution experienced

\footnotetext{
${ }^{1}$ Wheat products contribute approximately $54 \%$ to daily caloric intake and $35 \%$ to food expenditures.

${ }^{2}$ According to the Islamic Republic of Afghanistan (2010), in $2007 / 08$ approximately $36 \%$ of the population fell below the official poverty line.
}

declines in the quantity and quality of food consumed as a result of the 2008 wheat flour price increases. We find disparities in the behavioral responses of households based on where the household lies on the unconditional distribution of the particular food security measure of interest. Households at the top of the calorie distribution that can afford to cut back experience the largest declines in per capita daily caloric intake. The most vulnerable households at the bottom of the calorie distribution cannot afford to make substantial cuts to caloric intake since they are close to or below the minimum daily energy requirements; accordingly, we find no statistically significant decline in their caloric intake.

Households at the bottom of the dietary diversity distribution-often very poor households-experience the largest declines in dietary diversity as a result of the wheat flour price increases (though even households at the top of the distribution experience substantial declines). These households are likely unable to make major cuts to caloric intake, and thus must adjust the compositions of their diet to maintain energy levels. Such declines can exacerbate already high levels of malnutrition; Afghanistan is estimated to have extremely high levels of underweight $(33 \%)$ and wasting $(7 \%)$ in children (UNICEF 2008).

This article builds on the work of D'Souza and Jolliffe (2012), who show that in response to the wheat flour price increases Afghan households reduced the value of their food consumption, and that this reduction was the result of reducing the quality and quantity of food consumed in approximately equal proportions. We focus on the distributional dimensions of food security rather than geographic or net buyer/seller dimensions as done in D'Souza and Jolliffe (2012) and in much of the food price crisis literature. We also provide supplemental evidence on the impact of the price increases on key micronutrients and macronutrients, as well as the share of calories from non-staples.

In the next section, we discuss current evidence on the impact of high food prices and household responses. We then describe the utilized consumption and price data, the measures of food security, and our sample. In the following section, we describe the empirical specification and the UQR methodology. Then we present the main results, as well as supplemental results, supporting evidence 
on how households adapt, and caveats to the results. The final section concludes.

\section{The Impact of High Food Prices: Existing Evidence and Household Responses}

Most recent studies on high food prices rely on data collected during periods of relatively stable prices and use the limited variation in prices to estimate price elasticities. Simulation models are then used to estimate short-run effects of larger price shocks on measures of household welfare, primarily poverty rates, with many studies focusing on differences between outcomes for rural and urban areas. Examples include: Woden et al. (2008), who examine twelve African countries; Ivanic and Martin (2008), who examine nine low-income countries; Ul Haq et al. (2008), who examine Pakistan; Simler (2010), who examines Uganda; Robles and Torero (2010), who examine four Latin American countries; and De Hoyos and Medvedev (2011), who examine 73 low and middle income countries. In these studies, the magnitude of the impact of the crisis varies greatly across households and countries, depending on several characteristics including the degree of price transmission, dependence on food imports, whether staple foods are traded internationally, whether the household is a net buyer or a net seller of food, and the household's reliance on staples. But the general finding is similar: national poverty rates increase, with urban areas, on average, suffering larger increases.

There is a smaller body of literature, to which we contribute, that examines the impact of the recent high food prices on nutrition-related outcomes. ${ }^{3}$ Using data from eight developing countries, Anríquez et al. (2013) simulate the effects of staple food price increases on household undernourishment (falling below daily calorie thresholds) for the average household, for urban and rural households, and by expenditure decile. In general, mean calorie levels decline; however, countries vary in terms of who was hurt the most (e.g., the poorest or middle quintiles, or rural or urban populations) and in terms of the household-level determinants of the

\footnotetext{
${ }^{3}$ For a review of the literature on the impact of earlier crises on food security, food consumption, nutrition, and maternal and child health see Ruel et al. (2010).
}

nutritional responses. Tiwari and Zaman (2010) also find increases in undernourishment rates across all major developing country regions, assuming minimal levels of price transmission from international to domestic markets. Brinkman et al. (2010) examine the impact of high food prices (and the global financial crisis) on food consumption, nutrition, and health outcomes for specific developing countries, as well as several developing regions, and Bibi et al. (2009) find increases in food poverty and undernourishment for children in Mali.

From these poverty and nutrition simulation studies, it is largely impossible to separately identify the extent to which the simulated estimates result from actual changes in household wellbeing or from modeling assumptions. Most studies focus on the short-run, assuming that households and producers have no behavioral responses to the price increases, that there are no changes in input prices or wage rates, and that the proportional changes in consumer and producer prices are equivalent. In a recent contribution, Minot and Dewina (2013) demonstrate the sensitivity of poverty results to these standard assumptions.

The need to simulate welfare effects is driven (partially) by a lack of comparable data before and after the price increase. Our study represents one of a handful of empirical analyses that overcomes the need to simulate welfare effects by using nationally-representative household data collected prior to and during a significant price shock. For example, Friedman et al. (2011) use nationally-representative data from Pakistan to estimate reductions in calorie availability due to the 2008 food price spike, and find an $8 \%$ reduction between 2006 and the first half of 2008. These authors also find that rural households with access to agricultural land fared better than urban households. Examining the same price spike, and using nationally-representative rural household data from Bangladesh, Balagtas et al. (2012) find an increase in poverty rates and demonstrate changes in the determinants of poverty over time. Further, using nationally-representative data from South Africa, Jacobs (2010) finds increases in household hunger levels as a result of the food price and financial crises of 2007-2009. These studies employ various methodologies and focus on different household-level outcomes, but like the present article they are 
all able to observe (and estimate) behavioral responses in the presence of large increases in food prices rather than through modeling assumptions and simulations.

These observed changes in poverty and nutrition are driven, at the microeconomic level, by household behavior. In the face of food price increases (or other economic shocks), households may employ food-based coping strategies, non-food-based coping strategies, or a combination of both (Food and Agriculture Organization 2008). Foodbased coping strategies include reducing the quantity (e.g., smaller meals, less frequently), quality, and diversity of foods consumed by moving toward cheaper food groups and cheaper foods within food groups. Non-foodbased coping strategies include reducing non-food expenditures such as education and health, selling off assets, searching additional income-generation activities, changing household composition (e.g., sending children to live with relatives), and borrowing money.

Poorer and richer households may have different constraints on their abilities to cope. For example, richer households have more assets to sell in order to smooth consumption. In a recent contribution, Carter and Lybbert (2012) show that in response to weather shocks, poorer households fail to smooth total consumption as well as richer households do. ${ }^{4}$ Additionally, richer households may have more food-based coping strategies available since they usually consume a more diversified diet of relatively more expensive foods; they thus have the option to move toward cheaper foods and food groups as prices increase. In contrast, poorer households that consume the cheapest foods already may not have the option of substituting into other foods. Jensen and Miller (2008) demonstrate both theoretically and empirically that as prices rise, the poorest households are less able to move to other foods than households that are (even slightly) less poor.

There is some empirical evidence that by moving to cheaper foods (and employing non-food-based coping strategies) households may be able to maintain energy levels

\footnotetext{
${ }^{4}$ It is often assumed that poorer households smooth consumption in the face of shocks. However, using a poverty trap model, Carter and Lybbert (2012) show that below a critical wealth level, poorer households smooth (or protect) assets rather than consumption due to high marginal values of assets and the potential of future negative shocks.
}

despite food price increases. For example, Jensen and Miller (2008) find no reduction in calories among poor households in China's Hunan Province, and a very small reduction in calories among poor households in Gansu Province (though they cannot distinguish these reductions from typical seasonal declines), in response to food price increases in 2006. These authors find evidence of a movement away from relatively more expensive calorie foods and a slight reduction in some non-food expenditures. In contrast, Ruel et al. (2010) show that households reduce both the quantity and quality of food consumed in response to price shocks or other economic crises. Klotz et al. (2008) provide a more nuanced view, that is, households are likely to reduce the quality of food consumed before reducing the quantity of food consumed, and for this reason individuals will experience micronutrient deficiencies before weight loss.

When prices increase, poor households try to maintain calories, but when prices decrease, they are able to move away from staples to more expensive foods with other attributes (e.g., more nutritious, tastier, etc.). For example, Torlesse et al. (2003) show that rice prices and rice consumption per capita are not strongly correlated for Bangladeshi households; therefore, as rice prices fall, households reduce their rice expenditures and increase non-rice food expenditures, which lead to an increase in the quality of food consumed. Our empirical analysis adds to the literature that focuses on the foodbased-coping mechanisms employed by households in the face of food price shocks. In particular, we examine changes in caloric intake, dietary diversity, and several other measures of diet quality.

\section{Data}

We use consumption and price data from the National Risk and Vulnerability Assessment (NRVA) 2007/08, conducted by the Government of Afghanistan Central Statistics Organization and the Ministry of Rural Rehabilitation and Development. The survey was administered between August 2007 and September 2008, and covered over 20,500 households (over 150,000 individuals) in 2,572 communities in all 34 provinces of Afghanistan. The long time frame made it 
possible to obtain seasonally-representative estimates of household food security, and allowed for coverage of conflict-affected areas.

The sample was selected based on a stratified, multi-stage design. The survey was stratified explicitly geographically and implicitly over time. ${ }^{5}$ The 11 provinces with the most populous provincial centers were each stratified into urban and rural areas. The remaining provinces were treated as separate rural strata, and the nomadic Kuchi population was treated as a separate stratum. The stratification resulted in 46 domains, or strata. In the first stage of selection, 2,441 primary sampling units (PSU) were drawn from urban and rural settled populations, and 131 PSUs were drawn from Kuchi populations. In the second and final stage, eight households were selected from each PSU.

The implicit stratification over time is a key element of the survey's design. The population frame was sorted both spatially and temporally to ensure that (with systemic interval selection) the selected sample would be seasonally representative. ${ }^{6}$ Thus, each quarterly sample of the NRVA survey is representative at the national level. In a country where agriculture is an important form of livelihood, seasonal variations in consumption patterns are to be expected; thus, it is critical to capture nationallyrepresentative measures of household food security throughout the year. ${ }^{7}$ Additionally, the year-long fieldwork enabled enumerators to access households in conflict zones without compromising the survey design. Specifically, enumerators would try to secure permission informally from local leaders. When a PSU was considered too insecure to interview at the scheduled time, it would not be replaced immediately, but would be reconsidered at a later date within the quarter.

The NRVA consists of household and community questionnaires and a district market price survey. ${ }^{8}$ In this analysis, we exploit two

\footnotetext{
5 The population frame is based on a 2003-2005 national household listing.

6 See Kish (1965) for a discussion of implicit stratification.

7 Key demographic, educational and health, and infrastructure indicators across the four quarters are displayed in table A1 of the supplementary appendix online. While we observe some statistical differences in means across quarters, there is little evidence of systematic differences in the samples based on these generally time-invariant characteristics.

8 The household questionnaire includes 20 sections, 6 of which were administered by female interviewers to female household members, and 14 administered by male interviewers to the male
}

\section{Table 1. Population Means}

Age of household head

Number of males

Number of females

0.32

0.80

0.22

0.39

20,483

Total observations
Note: Population-weighted means with standard deviations in parentheses.

Source: NRVA $2007 / 08$.

key elements, that is, the food consumption data and the price data. The consumption data include the frequency and quantity of consumption of 91 food items over the previous week, including food bought on the market, or food produced or obtained through other means like food aid or gifts. The NRVA's broad coverage of foods, including seasonal varieties, allows for a better calculation of caloric and nutrient intake than surveys with fewer items. The price data include prevailing prices of the food items included in the consumption section, as well as domestic and imported grains and fuel. The local price data are important for obtaining accurate estimates of price effects in a mountainous country with poor infrastructure, where transportation and transaction costs vary greatly.

The effective sample size for our analysis is 20,483 households. ${ }^{9}$ Table 1 displays population averages of key household characteristics for the full sample over the survey year. On average, households have 8.6 members living in approximately 3.6 rooms (or tents for Kuchi populations). The typical

household head. Enumerators traveled in teams of two (one male and one female) since females are not able to travel by themselves in Afghanistan, and it is important that interviews be conducted among individuals of the same sex due to the strong cultural norms regarding separation between the sexes outside the family.

${ }^{9}$ The household response rate was $99.8 \%$, and the PSU replacement rate was $3 \%$. Thirty-two households were dropped due to missing female questionnaires; all of these households are located in four communities, suggesting a relatively small, systematic error in field operations. Fifty-two households were dropped due to missing consumption data and seven households were dropped due to missing asset data. One household is missing data on household size and is dropped because per capita measures of consumption and food security cannot be calculated. 
household consists of 2.1 men, 2 females, and 4.5 children (under 16). Heads of households are about 45 years old; nearly all are married, and most are illiterate. Approximately $80 \%$ of households reside in rural areas.

\section{Measures of Food Security}

According to the FAO (2008), "Food security exists when all people, at all times, have physical and economic access to sufficient, safe and nutritious food that meets their dietary needs and food preferences for an active and healthy life." Food security is comprised of four main pillars: availability, access, utilization, and stability. Availability refers to the physical existence of food, which relates to production, stocks, and trade. Access refers to a household's ability to obtain food, which depends on income, prices, and market access. Utilization refers to an individual's ability to process nutrients and energy from food; many factors contribute to food utilization, including dietary diversity and nutrient absorption, intra-household allocation of food, and hygienic preparation. The final factor refers to the stability of the other three factors over time and in response to shocks (FAO 2008).

We construct two main measures of household food security to be used as dependent variables in the regression analysis: per capita daily caloric intake, and household dietary diversity. The first measure relates to the access to food and is a widely used measure of health and undernutrition. The second measure relates to the utilization of food and has been shown to be linked to the nutritional status of children and adults (Arimond and Ruel 2004; Ruel 2003; Steyn et al. 2006). The estimated changes in these two measures provide evidence of the instability (fourth pillar) of food security in Afghanistan.

We use the FAO Food Composition Tables for the Near East to convert daily food quantities into kilocalories; we then divide by the effective household size to obtain per capita daily caloric intake. ${ }^{10}$ The effective number of household members incorporates guests eating meals within the home, and excludes members not regularly eating meals at home. ${ }^{11}$ The effective number of household

\footnotetext{
10 Spices, water, and "other" foods do not contribute to total calories. The USDA sources were used for a few items that were not available in the FAO tables.

11 Some studies use household size to calculate per capita amounts but the prevalent custom of sharing meals in Afghanistan
}

members is greater than household size for the relatively richer households, and less than household size for the poorest households.

To measure household dietary diversity, we use the food consumption score (FCS) developed by the World Food Programme (WFP) and used in food security assessments throughout the world. This score is a weighted sum of the frequencies with which households consumed foods within eight food groups over the previous week. ${ }^{12}$ The food groups include grains, pulses, vegetables, fruit, meat/fish, milk/dairy, sugar, and oil/fat. Higher scores denote a more varied diet and are suggestive of a higher quality diet with a potential for higher micronutrient intake.

Table 2 presents population statistics on the two indicators by decile (for the survey year and by quarter) and demonstrates the precarious nature of food security in Afghanistan. Nearly $30 \%$ of Afghan households fail to meet the conventional nutritional benchmark of 2,100 calories per day, while those at the top of the calorie distribution are well above the threshold. Mean per capita daily caloric intake is approximately 2,601. ${ }^{13}$ This estimate is in line with worldwide calorie estimates using macroeconomic data; from 2007 to 2009 , average daily calories per capita were 2,810 worldwide, 2,670 in developing countries, and 2,380 in South Asia (excluding Afghanistan and Bhutan; FAO 2012). ${ }^{14}$ The mean per capita daily caloric intake is also in line with estimates from nationally-representative household data for the region; daily calories per capita ranged between 2,392 and 2,593 in Pakistan between 2005 and 2008 (Friedman et al.

makes it important to account for guests eating meals from the household cooking pot. We do not use equivalency scales to account for differences in consumption of adults and children when calculating measures of wellbeing, but rather opt to include variables for household composition directly into the regression model to control for such differences.

12 Weights for the food groups range from 0.5 to 4 based on nutrient density. Condiments receive zero nutritional weight. Frequencies are truncated at 7 for each food group. The measure ranges from 0 to 112 .

${ }^{13}$ We assume this is a slight overestimation due to some food waste and telescoping (inclusion of consumption just outside of the reference period). Deaton and Kozel (2005) note that in the case of India, a 7-day food recall period produces higher daily food estimates than a 30-day recall period. We elaborate on potential measurement error in the results section.

14 FAOSTAT provides estimates of dietary energy supply (in kilocalories per person, per day), averaged over three years and weighted by population. These estimates are calculated using macroeconomic supply data and may be less reliable than estimates derived from household survey data. 
Table 2. Population Statistics across the Distribution and Survey Year

\begin{tabular}{lrrrrrrrrrr}
\hline Quantile & 10th & 20 th & 30th & 40th & 50 th & 60th & 70 th & 80th & 90th & Mean \\
\hline Full survey year & & & & & & & & & \\
Daily per capita caloric intake & 1,695 & 1,937 & 2,113 & 2,279 & 2,441 & 2,629 & 2,861 & 3,166 & 3,688 & 2,601 \\
Food consumption score & 34 & 42 & 49 & 56 & 61 & 66 & 71 & 78 & 88 & 61 \\
Quarter 1 & & & & & & & & & & \\
Daily per capita caloric intake & 1,740 & 1,992 & 2,236 & 2,452 & 2,679 & 2,938 & 3,240 & 3,628 & 4,262 & 2,885 \\
Food consumption score & 40 & 50 & 57 & 64 & 69 & 74 & 79 & 86 & 95 & 68 \\
Quarter 2 & & & & & & & & & & \\
Daily per capita caloric intake & 1,764 & 2,030 & 2,234 & 2,414 & 2,589 & 2,780 & 3,022 & 3,322 & 3,835 & 2,725 \\
Food consumption score & 34 & 41 & 47 & 55 & 60 & 66 & 72 & 80 & 92 & 61 \\
Quarter 3 & & & & & & & & & & \\
Daily per capita caloric intake & 1,663 & 1,899 & 2,062 & 2,217 & 2,351 & 2,499 & 2,678 & 2,937 & 3,311 & 2,446 \\
Food consumption score & 32 & 40 & 47 & 53 & 58 & 63 & 69 & 75 & 83 & 58 \\
Quarter 4 & & & & & & & & & & \\
Daily per capita caloric intake & 1,610 & 1,873 & 2,023 & 2,144 & 2,279 & 2,426 & 2,617 & 2,861 & 3,263 & 2,387 \\
Food consumption score & 33 & 42 & 49 & 55 & 59 & 63 & 67 & 71 & 79 & 58 \\
\hline
\end{tabular}

Note: Population-weighted estimates at each decile and at the mean, for the survey year and by quarter.

Source: NRVA 2007/08

2011), and 2,536 in Nepal from 2010 to 2011 (National Planning Commission and Central Bureau of Statistics 2013).

The mean food consumption score is 61 , ranging from 34 at the bottom decile to 88 at the top decile. The WFP uses a cutoff of 48 for an acceptable diet in countries where most households consume staples and oil every day. Under this categorization, approximately $80 \%$ of the population have acceptable diets, which is consistent with food security assessments conducted by the WFP for several other developing countries in recent years. Based on these assessments, the percentage of households with acceptable diets are as follows: Uganda, $78 \%$ in 2013; Rwanda, 79\% in 2012; Malawi, $75 \%$ in 2010/11; Cambodia, $81 \%$ in 2008; and Pakistan, $82 \%$ in 2008. ${ }^{15}$ Recent work suggests that the cutoff points for the FCS classifications may be too low, for example, when compared to estimates of calorie deficiency (Weismann et al. 2009).

\section{Stability of Food Security}

According to the FAO (2006), "To be food secure, a population, household or individual must have access to adequate food at all times. They should not risk losing access to food as a consequence of sudden shock (e.g., an economic or climatic crisis) or cyclical events (e.g., seasonal food insecurity)."

\footnotetext{
15 Estimates are drawn from WFP reports, available at http://www.wfp.org/food-security/assessment-bank.
}

An examination of the raw data over the four quarters of the survey year (table 2) reveals the instability of household food security in Afghanistan.

We observe large declines in caloric intake and dietary diversity for households across the distributions, with the worst levels observed in quarters three and four. Households at the top of the caloric intake and dietary diversity distributions experience the largest declines in food security in percentage terms, while those households at the bottom of the distributions seem to experience only minor declines in food security. It is important to note that the most food insecure households consume relatively poor diets, and even small declines in quantity and quality of food consumed could have major repercussions for short-term nutrition, and even long-term nutrition in the case of children in early developmental stages.

Overall, the percentage of the population consuming less than 2,100 calories per day (a conventional nutritional benchmark) increased from 24 in the fall of 2007 to 34 in the summer of 2008. These patterns support evidence on increases in the poverty rate reported by the Government of Afghanistan; the official poverty rate increased from $23.1 \%$ in the fall of 2007 to $46 \%$ in the summer of 2008 (Islamic Republic of Afghanistan 2010). These raw data suggest, and the regression results below confirm, that the large price increases in 2008 represented a "shock" that reduced access to food and dietary diversity of Afghan households. 


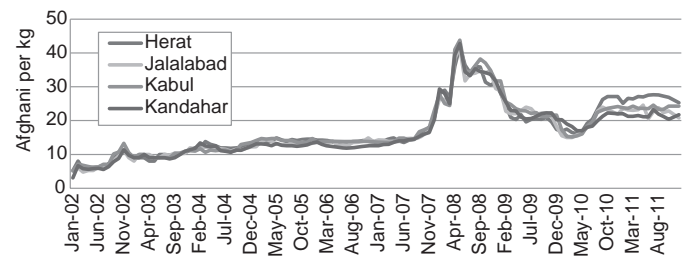

Figure 1. Retail wheat flour prices,
2002-2011

\section{Price Data}

Our analysis focuses on the price of domestic wheat flour, which is the form of wheat most commonly purchased by households. Most wheat is consumed in the form of naan, a type of unleavened bread prepared by households with either refined wheat flour or whole grain wheat (Chabot and Dorosh 2007). Wheat and other grains represent $48 \%$ of food expenditures and $70 \%$ of calories consumed; Afghan households spend about $60 \%$ of their budgets on food.

In 2008, due to a combination of international (increasing global food prices), regional (export bans in key trading partners like Pakistan), and domestic (drought) factors, domestic wheat flour prices approximately doubled. In the empirical work below, we estimate the marginal effects of the total price increases because we are unable to disentangle the effects due to each factor. An additional factor that may have played a role in the price spike is typical seasonal variation given that harvest season falls approximately in quarter three; however, we do not believe that seasonality was a major driver of the price increases. Figure 1 displays the retail prices of wheat flour in four major urban centers from 2002 to 2011, collected by the FAO Global Information and Early Warning System (GIEWS). We first note the major price spike starting in early 2008 and peaking around summer 2008. Second, we note that the price spike was magnitudes larger than observed seasonal variation in prices. In fact, there is little evidence of large monthly price fluctuations based on the harvest calendar. $^{16}$

\footnotetext{
16 Given the transportation costs, it is likely that there is more price fluctuation in remote areas. However, if seasonal patterns were very important, we should observe them in these major urban areas in the years prior to the 2008 spike, but we do not.
}

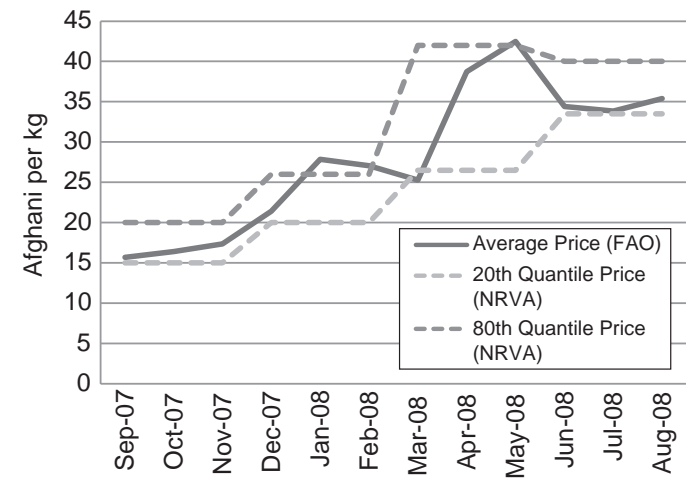

Figure 2. Retail wheat flour prices from FAO and NRVA over survey year

In the empirical work that follows, we use price data from the NRVA district price survey. Figure 2 plots the $80^{\text {th }}$ and $20^{\text {th }}$ quantiles of wheat flour prices from the NRVA data over the survey timeframe, along with the average retail wheat flour price collected by FAO from the four urban centers. The NRVA and FAO price data display similar patterns during the survey year, with the average FAO price falling between the top and bottom quintiles of the NRVA wheat flour price data.

Table 3 displays the (average) price of domestic wheat flour from the NRVA data over the survey year; it also includes other important commodities that we use in the regression analysis to control for simultaneous price increases. ${ }^{17}$ We chose milk, lamb, rice, and vegetable oil because they represent several key food groups and because, along with wheat flour, these five food groups make up a large percentage of monthly household food expenditure; for example, relatively poor people $\left(20^{\text {th }}\right.$ to $50^{\text {th }}$ quantile of the total consumption distribution) spend $80 \%$ of their food expenditure on these food items. We also include kerosene because it is the most commonly used cooking fuel.

\section{Methodology}

We estimate the following reduced-form model of the impact of the wheat flour price

\footnotetext{
17 Prices are aggregated to the stratum level to mitigate potential measurement error in district-level prices. Strata are based on urban and rural designation within provinces.
} 
Table 3. Average Prices by Quarter and over the Survey Year

\begin{tabular}{lcccrr}
\hline & $\begin{array}{c}\text { Quarter 1 } \\
\text { (Fall) }\end{array}$ & $\begin{array}{c}\text { Quarter 2 } \\
\text { (Winter) }\end{array}$ & $\begin{array}{c}\text { Quarter 3 } \\
\text { (Spring) }\end{array}$ & $\begin{array}{c}\text { Quarter 4 } \\
\text { (Summer) }\end{array}$ & $\begin{array}{c}\text { Survey } \\
\text { Year }\end{array}$ \\
\hline Price of domestic wheat flour & 18.09 & 23.52 & 34.19 & 36.51 & 28.45 \\
Price of vegetable oil & 64.81 & 76.93 & 88.90 & 91.70 & 81.16 \\
Price of domestic rice & 33.93 & 33.99 & 46.16 & 55.29 & 42.77 \\
Price of lamb & 182.34 & 186.20 & 189.28 & 180.27 & 184.44 \\
Price of milk & 23.44 & 25.66 & 27.23 & 30.75 & 26.94 \\
Price of kerosene & 43.15 & 45.77 & 46.82 & 55.48 & 48.12 \\
\hline
\end{tabular}

Note: Population-weighted means. Prices in Afghani per kilogram or liter. Source: NRVA 2007/08.

increases on household food security:

$$
\begin{aligned}
\log \left(f_{s_{h}}\right)= & \beta_{0}+\beta_{1} \\
& \times \log \left(\text { price wheat flour }{ }_{a p q}\right) \\
& +\theta \log \left(\text { prices }_{a p q}\right)+\alpha \mathbf{H H}_{h} \\
& +\delta \mathbf{D I S T}_{d q}+\Pi_{p}+\varepsilon_{h}
\end{aligned}
$$

where $h$ denotes household, $a$ denotes area (urban or rural), $d$ denotes district, $p$ denotes province, and $q$ denotes quarter. The variable $f s$ is either daily per capita caloric intake or the food consumption score. The variable prices represents a vector of commodity prices, HH represents a vector of household characteristics, DIST represents a vector of district-level variables, $\Pi$ denotes province dummy variables, and $\varepsilon$ is an idiosyncratic error term. $^{18}$

To isolate the effect of changes in wheat flour prices, we control for simultaneous price increases in other important commodities since household purchasing decisions are based on relative price movements, and since omitting such variables could bias our coefficient of interest. ${ }^{19}$ The price vector includes the prices of milk, lamb, rice (a potential substitute for wheat flour, though not commonly consumed in Afghanistan), vegetable oil, and kerosene for reasons described above.

We include the following household characteristics in the model: a dummy for agricultural households (households that

\footnotetext{
18 For our OLS estimates, we use a standard Huber-White correction to estimate the sampling variance, which allows for correlation of the residuals within PSUs. In addition, the standard errors are corrected for stratification. For estimating the sampling variance of the UQR estimator, we use a PSU-level bootstrap (1,000 replications), which accounts for correlation of the residuals within the PSUs, but does not account for the stratification.

19 Given that food prices are often positively correlated with each other and negatively correlated with caloric intake, omitting the other food price variables would lead to a negative bias on the coefficient of the $\log$ of wheat flour price.
}

report owning or operating agricultural land); log values of durable assets, housing, and livestock; age of household head; dummy for households in which heads are literate; dummy for households in which heads are married; and, separately, the numbers of men, women, and children. We include the agricultural household dummy as a proxy for net sellers of food. We also include the household composition variables to control for differences in consumption requirements between children and adults, and for economies of scale in consumption. ${ }^{20}$

The asset values are intended to control for wealth effects and are assumed to be quasifixed in the short run. The value of durable goods is estimated based on a detailed inventory of household assets; this value accounts for depreciation and the opportunity cost of the funds tied up in the good. The value of housing is estimated using a hedonic model based on characteristics of the structure, as well as the location, to derive an imputed rental value. ${ }^{21}$ All currency values are in Afghani.

At the district level, we include dummies for topography using plateau and mountainous areas (plains areas make up the excluded category). Topographical characteristics are related to both agricultural yields and access

\footnotetext{
${ }^{20}$ An alternative approach to account for such differences employs equivalence scales that account for nutritional requirements based on age and, sometimes, gender when calculating per capita measures. See, for an early example, Buse and Salathe (1978). An advantage of including household composition in the specification, rather than using equivalence scales, is that this method allows the data to specify the parameterization of the scales. Results using equivalence scales, following Cutler and Katz (1992), are qualitatively similar to the main results.

21 The estimated housing value is the log of imputed, monthly rental value based on a hedonic model of the housing structure. The log value of assets is a self-assessed valuation based on a list of 13 assets including items such as stoves, refrigerators, radios, sewing machines, and bicycles. For details of the estimation, see Islamic Republic of Afghanistan, Central Statistics Organization, et al. (2011).
} 
to markets, and thus can affect a household's level of food security. To control for observable and unobservable time-invariant province-level factors that could confound the results, we include province dummy variables. While this method does not control for time-varying province characteristics, it does control for factors such as instability and conflict that may be present in certain provinces throughout the survey year.

\section{Model Estimation}

We estimate the parameters above using the unconditional quantile regression (UQR) estimator proposed by Firpo, Fortin, and Lemieux (2009). The estimator allows the marginal effects to vary based on a household's location on the unconditional distribution of the dependent variable. For comparison, we also estimate the parameters using OLS, a commonly used tool in policy analysis that provides a first step in understanding key relationships in the data. OLS provides the marginal effect for the mean household. By construction, these effects are constant over the entire distribution of the food security indicator and thus cannot elucidate heterogeneous effects for subsets of households. $^{22}$

The UQR estimator is based on influence functions, which were introduced by Hampel (1988) as a tool in robust estimation techniques. ${ }^{23}$ Using notation (largely) from Firpo, Fortin, and Lemieux (2009), consider some distributional statistic, $v\left(\mathrm{~F}_{\mathrm{y}}\right)$, such as the median, inter-quantile range, or any quantile. The influence function, $\operatorname{IF}\left(\mathrm{Y} ; v, \mathrm{~F}_{\mathrm{y}}\right)$, represents the influence of an individual observation on the distributional statistic, $v\left(\mathrm{~F}_{\mathrm{y}}\right)$, where $\mathrm{Y}$ is the dependent variable. $\mathrm{A}$ key innovation is that the authors add $v\left(\mathrm{~F}_{\mathrm{y}}\right)$ to the influence function to center it; this new function is called a re-centered influence function (RIF). By design then, the expectation of the RIF at the $\tau^{\text {th }}$ quantile is the

\footnotetext{
${ }^{22}$ We do not know, ex ante, whether the UQR estimator will provide qualitatively different information than OLS. There is some evidence that the conditional quantile regression estimator provides substantively different estimates. For example, Koenker and Bassett (1982) show that in the presence of a heteroscedastic error distribution, the quantile estimator will typically differ from the OLS estimator.

${ }_{23}$ Robust statistics are statistics and estimators that are not heavily influenced by deviations from model assumptions, nor alternatively, heavily influenced by single observations. Influence functions provide a formal way of measuring the extent to which a particular estimator is affected by a single observation in the sample.
}

value of the distributional statistic at the $\tau^{\text {th }}$ quantile (e.g., the median if $\tau=50$ ); or, more formally, $\mathrm{E}\left(\mathrm{RIF}\left(\mathrm{Y} ; v, \mathrm{~F}_{\mathrm{y}}\right)\right)=v\left(\mathrm{~F}_{\mathrm{y}}\right)$.

Firpo, Fortin, and Lemieux (2009) define $m_{\tau}(X)=\mathrm{E}\left(\mathrm{RIF}\left(\mathrm{Y} ; \tau, \mathrm{F}_{\mathrm{y}}\right) \mid \mathrm{X}\right)$ as the unconditional quantile regression model. ${ }^{24}$ The RIF regression parameter estimates are unconditional quantile marginal effects (UQME), or partial derivatives with respect to the price of wheat flour, as described by the following expression:

$$
\frac{\partial Q_{f s}(\tau)}{\theta \text { price wheat flour }}
$$

where $Q_{f_{s}}$ is the unconditional quantile function of our food security indicator and represents quantiles of the unconditional distribution. For our analysis, we estimate the marginal effects at all deciles $\left(10^{\text {th }}, 20^{\text {th }}, \ldots, 90^{\text {th }}\right)$ of the food security indicator distributions while controlling for the covariates in our model specification. The large observed variations in our two food security indicators (table 2) suggest that the UQME may differ for households at both the bottom and top of the distributions.

An alternative to the UQR is the Conditional Quantile Regression (CQR; Koenker and Bassett 1978) estimator, which allows behavioral responses to vary across the distribution of the dependent variable after conditioning on the observed covariates (e.g., see Chamberlain 1994). This estimator is based on the conditional population distribution, but policy questions are typically phrased in the context of the unconditional distribution. $^{25}$ For example, policy makers may be interested in knowing how price shocks affect caloric intake for households

\footnotetext{
24 Firpo, Fortin, and Lemieux (2009) provide an estimation method based on transforming the dependent variable into the re-centered influence function, and then using OLS estimation. They show that this approach yields a consistent estimator of the average marginal effect, $\mathrm{E}[\mathrm{d} \operatorname{Pr}[\mathrm{Y}>\tau \mid \mathrm{X}] / \mathrm{dX}]$, if $\operatorname{Pr}[\mathrm{Y}>\tau \mid \mathrm{X}=\mathrm{x}]$ that is linear in $\mathrm{x}$. To estimate the standard errors, we follow Firpo, Fortin, and Lemieux (2009) and use a bootstrap estimator of the sampling variance. For the interested reader, Firpo, Fortin, and Lemieux (2009) derive the asymptotic properties of the estimator and provide the analytical standard errors.

25 As an exception to this assertion, Buchinsky (1994) provides an example in which the question posed is best answered by the CQR estimator, and not something akin to the UQR. Buchinsky examines the distribution of wages in the United States, and, using the CQR estimator, provides insight into how wage inequality within-groups (i.e., conditional on being in a specific group) changes over time.
} 
at the bottom $20^{\text {th }}$ percentile of the calorie distribution of the total population, but not the conditional $20^{\text {th }}$ percentile. A key distinction between the two is that the bottom of the unconditioned distribution consists of those who have very low caloric intake, whereas the conditioned distribution need not have low caloric intake (just low caloric intake conditional on their attributes, such as education level). The estimated marginal effects based on the unconditioned distribution can be valuable in targeting safety net and poverty-alleviation programs, as well as allocating resources in general. ${ }^{26}$

\section{Results and Discussion}

\section{Unconditional Quantile Regression Results}

Table 4 shows that an increase in the price of wheat flour is associated with statistically significant declines in caloric intake and dietary diversity across the deciles of the respective unconditional distributions (UQR estimates) and at the means (OLS estimates). ${ }^{27}$

We observe the largest percentage decline in calories for the richest Afghan households - in terms of caloric intakewith smaller declines observed as one moves lower on the distribution scale. ${ }^{28}$ At a very basic level, richer households have more to give, as they are well above daily energy (calorie) requirements; they also host more guests and eat more away from home, on average, than poorer households. ${ }^{29}$ Households at the first decile of caloric intake are

\footnotetext{
${ }^{26}$ We present results using the conditional quantile regression estimator in the supplementary appendix online (table A2); the observed signs and significance of the results are similar to our main results, though with some differences in the magnitudes.

27 The tables display the coefficients of interest. Full results can be found in the supplementary appendix online, tables A3-A5.

${ }^{28} \mathrm{We}$ note here the standard caution that the regression coefficients represent the estimated effects from small, marginal price changes. This caution against using estimated marginal effects as a basis for simulating large, non-marginal price changes is particularly warranted in the case of quantile estimators, where different estimated effects across the distribution of the dependent variable imply a changing shape of this distribution due to price changes. Variation in the estimated marginal effects at different points on the distribution can readily imply re-rankings of observations (in terms of the dependent variable) with large enough simulated changes. But this exercise would be nonsensical, as one would expect that as the shape of the distribution changes, so too would each of the estimated marginal effects.

29 Households in the top quintile of the calorie distribution spend nearly twice as much on food away from home as households in the bottom quintile. They also provide more meals (approximately two) to guests.
}

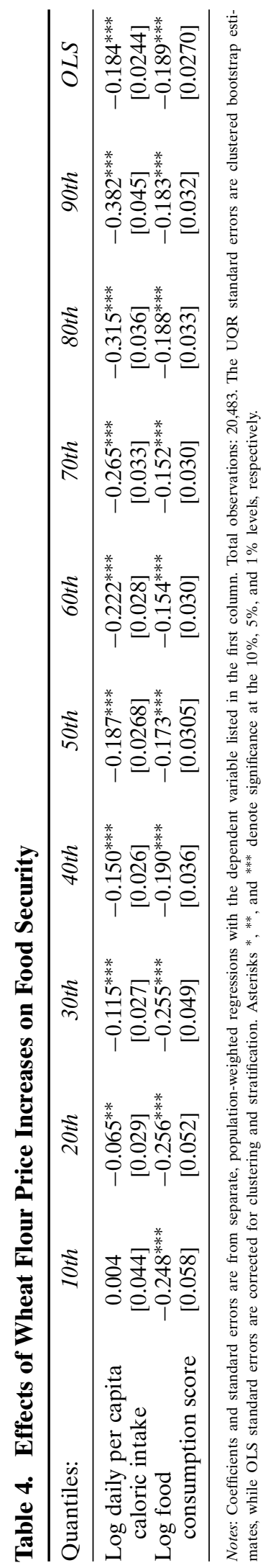


(a)

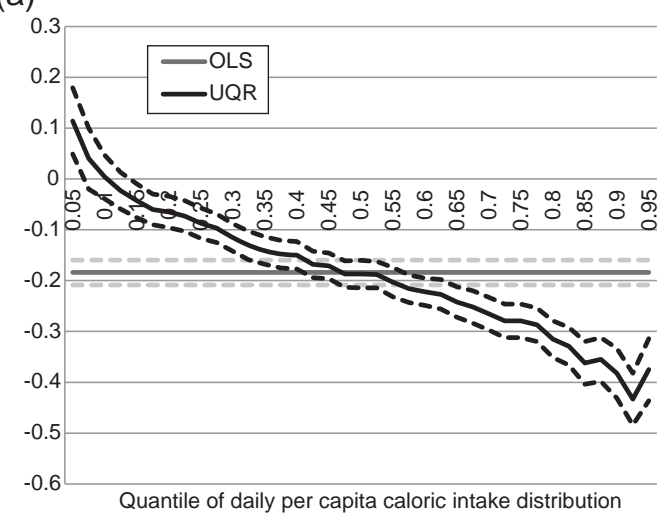

(b)

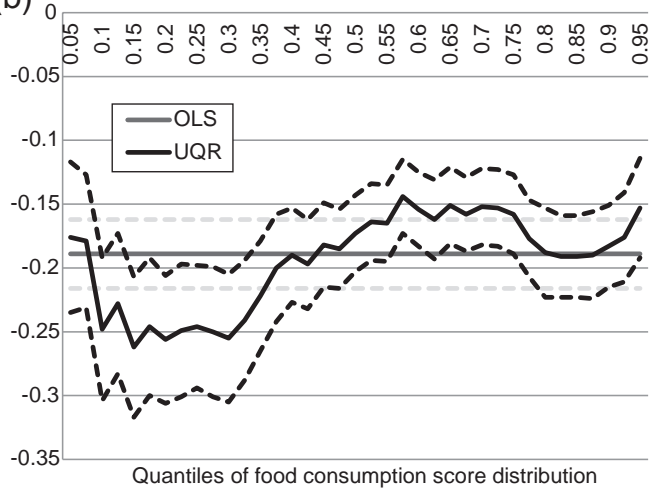

Figure 3. (a) Calorie-price effects (with $95 \%$ confidence bands) (b) Dietary diversity-price effects (with $95 \%$ confidence bands)

living below the threshold of energy requirements (with average daily per capita caloric intake of 1,670) and presumably are unable to cut back on calories without suffering serious nutritional consequences. Accordingly, we find no evidence of a decline in their caloric intake. Even those at the second decile experience negligible changes, equivalent to less than one-third of a standard naan (one piece of Afghan bread). ${ }^{30}$

The strong pattern of the calorie-price effects stands in contrast to the standard result in the literature that poorer households have larger food price elasticities. ${ }^{31}$ The standard result hinges on the fact that richer households devote a much smaller

\footnotetext{
30 Sulaiman et al. (2009) find that, in response to food price increases, Bangladeshi households at the third and fourth income quintiles experience more wasting than the poorest households

31 The elasticities are not completely comparable, since we look at calorie price elasticities based on where the household lies on the calorie distribution, and analyses in the literature often focus on demand for food based on a household's income quintile.
}

share of their budgets to food, and thus are not as affected by food price increases as poorer households. However, in Afghanistan food (and wheat in particular) makes up a large portion of the budget for rich and poor households alike. ${ }^{32}$ Indeed, over $80 \%$ of the population spends more than half of their total budget on food. Those in the bottom quintile of the income distribution spend approximately $66 \%$ of their budget on food (44\% on wheat flour), and even those in the top quintile spend approximately $49 \%$ of their budget on food ( $20 \%$ on wheat flour). Given the importance of food in the Afghan budget, it is plausible that even those households at the top of the calorie distribution range could be affected significantly by wheat flour price increases.

The estimates from the food consumption score (FCS) regressions reveal that Afghan households had to make large concessions in dietary quality as a result of the food price increases. ${ }^{33}$ Households at the bottom of the dietary diversity distribution made larger reductions in the diversity of their diets relative to those at the top of the distribution, though the declines are similar. These findings indicate that households changed the composition of their diets, perhaps by cutting back on more expensive, nutrient-rich foods, and moving toward cheaper foods. A shift towards a lower quality diet can have potentially serious implications for groups that have high nutrient requirements, such as children during developmental stages, pregnant and lactating mothers, and the elderly.

Our overall findings on food security are consistent with the literature on the impact of economic shocks on nutritional outcomes. For example, Klotz et al. (2008) argue that during times of economic crisis and when households cannot increase the amount that they spend on food, they are forced to cut back on expensive, micronutrient-rich foods to maintain their consumption of core staples. Therefore, economic shocks will lead to micronutrient deficiencies before weight

\footnotetext{
32 Food budget shares are high in many developing countries. According to the 2005/06 Uganda National Household Survey, the top and bottom income quintiles spent approximately $30 \%$ and $59 \%$, respectively (FAO 2012). According to the 2004/05 Indian Consumption Expenditure Surveys, the top and bottom income quintiles spent about $35.4 \%$ and $66.3 \%$, respectively (FAO 2012). In comparison, the top and bottom quintiles of U.S. households spend $11.4 \%$ and $16.2 \%$ on food (Schnepf and Richardson 2011).

33 Brinkman et al. (2010) find similar declines in the FCS in response to increases in rice prices for Haiti.
} 
loss. Similarly, Jensen and Miller (2008) find that in the face of food price inflation, poor urban households in China substitute toward cheaper foods. Further, using data from West Africa, Diagana et al. (1999) find decreases in levels of dietary diversity and changes in food consumption patterns after the 1994 devaluation of the CFA franc.

\section{Ordinary Least Squares Results}

The OLS coefficients provide the estimated response for the average household. Similar to the results in D'Souza and Jolliffe (2012), the estimated decline in caloric intake is similar in magnitude to the estimated decline in dietary diversity. ${ }^{34}$ We interpret these results as a quality for quantity trade-off that households make in order to maintain energy levels when faced with declining purchasing power. ${ }^{35}$

While the OLS results do show a decline in household food security levels, they do not allow us to observe the behavior of the most vulnerable households. Figures $3 \mathrm{a}$ and $3 \mathrm{~b}$ depict the UQR and OLS point estimates, and $95 \%$ confidence intervals for the calorie and dietary diversity regressions, respectively. Substantial differences exist between the UQR and OLS estimates for the calorie regressions. OLS overestimates the impact

\footnotetext{
${ }^{34}$ The coefficients are larger in magnitude than those in D'Souza and Jolliffe (2012) due to differences in the specification, but the general finding that calories and diversity decline by approximately equal levels is the same. The current specification differs in two ways: (i) we use asset measures instead of total per capita consumption quintiles to control for wealth and socio-economic status, and (ii) we include household composition variables in the main specification instead of as a robustness check. One concern with using consumption quintiles is that food consumption is one component of total consumption. Thus, including total consumption in any form would introduce endogeneity bias. We are grateful to a conference discussant for noting that, even more importantly, including the consumption quintiles only allows the price effect to pick up variation within consumption quintiles and not across quintiles. In lieu of consumption, we now use multiple measures of assets to control for wealth and socioeconomic status, and we treat these as fixed in the short run (i.e., not immediately linked to food consumption). The current specification is preferable because it allows the price effect to reflect within-quantile and between-quantile impacts.

35 By construction, the OLS coefficient is constant for all households, so we can interpret the results as the same household trading off the quality of food purchased in order to obtain enough food under the higher prices. Since the UQR coefficients are related to a specific quantile of a specific distribution, we cannot link the results for the calorie and dietary diversity regressions. More specifically, households that fall at a certain quantile on one distribution do not necessarily fall at the same quantile on the other distribution. Therefore, each coefficient must be interpreted carefully, acknowledging that while households may be trading quality for quantity, we cannot provide direct evidence using the UQR.
}

of the price increases on households in the lower portion of the distribution, and underestimates the impact on households in the upper portion of the distribution. Looking solely at the OLS results, policy makers would assume that all households, including the most vulnerable, reduce their caloric intake in response to the price increases. This could lead to blunt policy responses that focus on the provision of the staple food. These sorts of policies would not only exacerbate the price shock by shifting up demand (through government purchases), but they are likely to be a relatively more expensive safety net option (given the price increase of the staple). More importantly, the UQR results show that the most vulnerable households do not cut back on calories, and thus other policies may be more beneficial. It is likely that some of these households were forced to make other concessions, such as moving to lower quality and/or less nutritious foods; in such a case, interventions like nutrient supplementation programs or the fortification of staple foods could better address the needs of those households.

\section{Supplemental Indicators of Diet Quality}

To further explore the impact of the wheat flour price increases on food security, we examine several supplemental indicators of diet quality. First we scrutinize direct measures of nutrition, that is, the intake of key nutrients. Then we look at an indirect measure of nutritional sufficiency, that is, the share of calories from non-staples. For each indicator, we examine the change in nutrient intake due to an increase in wheat flour prices based on the household's position on the unconditional distribution of the respective nutrient intake variable.

We examine three essential micronutrients (retinol, beta-carotene, iron) and the three macronutrients (protein, carbohydrates, fat). Retinol and beta-carotene are forms of vitamin A, which is an important nutrient for vision and immune system functions. Iron is critical in growth and development, immune system functions, and overall metabolism. Both vitamin $\mathrm{A}$ and iron deficiencies are ubiquitous in developing countries, and have been recognized as major public health challenges (Dufour and Borrel 2007; Fanzo and Pronyk 2010; Ramakrishnan 2002). The three macronutrients provide energy 
(or calories) to the body and are essential-in large quantities-for survival.

For some micronutrients (retinol and beta-carotene in particular), we observe zero intakes. Instead of transforming by taking logs of the micronutrient data and adding some small value to the zero values, we use the inverse hyperbolic sine (IHS) transformation, which reduces the importance of extreme observations in a manner similar to taking logs, but has the additional benefit of being well-defined at zero values. The IHS transformation, first proposed by Johnson (1949), was introduced to econometrics by Burbidge, Magee, and Robb (1988). ${ }^{36}$ Since then it has been used as an alternative to log transformations for the dependent variable (Burbidge, et al. 1988) and for explanatory variables (Layton 2001), with variables that can take on zero or negative values. We calculate the IHS of each nutrient and then use the UQR estimator; the rest of the model remains the same.

We observe declines in micronutrient and macronutrient intakes in response to the wheat flour price increases (table 5). The results differ by the type of nutrient, as well as the position of a household on the distribution of nutrient intake. We find declines in iron, retinol, and beta-carotene for most households, with the exception of the lowest deciles of the distributions (and, for betacarotene, those in the top deciles as well). The general declines are consistent with Ecker and Qaim (2011), who find negative staple food price elasticities (at population means) for iron and vitamin A (and protein) in Malawi.

In terms of macronutrients, we find declines in protein, fat, and carbohydrates, with larger declines in the former two macronutrients, which may be expected since calories from protein and fat are relatively more expensive than calories from carbohydrates. We find that households at the lower ends (e.g., first and second deciles) of these distributions do not experience statistically significant declines. We further separate protein into that derived from animal-source foods and that derived from non-animalsource foods. Animal-source and nongrain food expenditures have been linked to lower levels of malnutrition, measured by child stunting rates (Sari et al. 2010). We find that

\footnotetext{
${ }^{36}$ The IHS function is defined as $\sinh ^{-1}=\log \left(x+\left(x^{2}+1\right)\right)^{\frac{1}{2}}$.
}

animal-source protein declines by much more than non-animal-source protein; the former is a more expensive source of calories than the latter. The largest change overall is the decline in protein from animal sources for those consuming at the lowest decile. Across each of the deciles, the negative elasticity of protein from animal sources is the largest change of the macronutrients. These findings are consistent with the fact that as purchasing power declines, households move away from more expensive and often nutritious calories such as meat, to cheaper, less nutritious ones such as pulses and beans. The findings are also consistent with previous literature on economics shocks. Martin-Prevel et al. (2000) and Block et al. (2004) find reductions in maternal and child nutritional status following a currency devaluation and a financial crisis, respectively.

As an additional indicator of diet quality, we use the share of calories from nonstaples. $^{37}$ In a recent paper, Jensen and Miller (2010) propose using the share of calories from staples (SCS) as an indicator of nutritional sufficiency. The authors argue that once an individual has fulfilled his or her caloric requirement (subsistence), he or she will begin to substitute toward non-staple foods with more non-nutritional attributes such as taste. Therefore, the SCS can be used to gauge an individual's level of undernutrition, or poor quality diet. Jensen and Miller also show that the SCS is negatively associated with income in their sample of households in two Chinese provinces. In the Afghan population, the mean SCS is $70 \%$, with poor households in the bottom decile of the consumption distribution having an SCS of $78 \%$. Similarly, Jensen and Miller (2010) find the poorest households in their sample have an SCS of approximately $80 \%$. In order to provide an additional measure of (good) dietary quality (as a complement to our measure of dietary diversity), we use one minus the SCS, or the share of calories from non-staples.

The results show a strong pattern; increases in wheat flour prices are associated with a decline in the share of calories from nonstaples (table 6). The results suggest that despite the increase in the price of a staple food, households are forced to increase the

\footnotetext{
37 We define staples as all grain products including, but not limited to, wheat.
} 
Table 5. Effects of Wheat Flour Price Increases on Micronutrient and Macronutrient Intakes

\begin{tabular}{|c|c|c|c|c|c|c|c|c|c|}
\hline Quantile: & 10th & 20 th & $30 t h$ & 40th & $50 t h$ & $60 t h$ & 70 th & $80 t h$ & 90th \\
\hline Iron & $\begin{array}{c}0.063 \\
{[0.054]}\end{array}$ & $\begin{array}{c}-0.003 \\
{[0.039]}\end{array}$ & $\begin{array}{r}-0.058^{*} \\
{[0.034]}\end{array}$ & $\begin{array}{c}-0.083^{* * *} \\
{[0.031]}\end{array}$ & $\begin{array}{c}-0.115^{* * *} \\
{[0.033]}\end{array}$ & $\begin{array}{c}-0.133^{* * *} \\
{[0.032]}\end{array}$ & $\begin{array}{c}-0.152^{* * *} \\
{[0.034]}\end{array}$ & $\begin{array}{c}-0.175^{* * *} \\
{[0.039]}\end{array}$ & $\begin{array}{c}-0.187^{* * *} \\
{[0.048]}\end{array}$ \\
\hline Retinol & $\begin{array}{c}-0.000^{* * *} \\
{[0.000]}\end{array}$ & $\begin{array}{c}-1.434^{* * *} \\
{[0.399]}\end{array}$ & $\begin{array}{c}-1.042^{* * *} \\
{[0.296]}\end{array}$ & $\begin{array}{c}-0.692^{* * *} \\
{[0.185]}\end{array}$ & $\begin{array}{c}-0.725^{* * *} \\
{[0.142]}\end{array}$ & $\begin{array}{c}-0.653^{* * *} \\
{[0.122]}\end{array}$ & $\begin{array}{c}-0.569^{* * *} \\
{[0.113]}\end{array}$ & $\begin{array}{c}-0.437^{* * *} \\
{[0.102]}\end{array}$ & $\begin{array}{c}-0.446^{* * *} \\
{[0.105]}\end{array}$ \\
\hline Beta-carotene & $\begin{array}{c}-0.14 \\
{[0.154]}\end{array}$ & $\begin{array}{c}-0.113 \\
{[0.150]}\end{array}$ & $\begin{array}{c}-0.14 \\
{[0.148]}\end{array}$ & $\begin{array}{c}-0.303^{* *} \\
{[0.124]}\end{array}$ & $\begin{array}{c}-0.334^{* * *} \\
{[0.107]}\end{array}$ & $\begin{array}{c}-0.339^{* * *} \\
{[0.101]}\end{array}$ & $\begin{array}{c}-0.281^{* * *} \\
{[0.093]}\end{array}$ & $\begin{array}{r}-0.168^{*} \\
{[0.100]}\end{array}$ & $\begin{array}{c}-0.078 \\
{[0.114]}\end{array}$ \\
\hline Carbohydrate & $\begin{array}{c}0.014 \\
{[0.050]}\end{array}$ & $\begin{array}{c}-0.032 \\
{[0.033]}\end{array}$ & $\begin{array}{c}-0.084^{* * *} \\
{[0.029]}\end{array}$ & $\begin{array}{c}-0.131^{* * *} \\
{[0.028]}\end{array}$ & $\begin{array}{c}-0.159^{* * *} \\
{[0.029]}\end{array}$ & $\begin{array}{c}-0.200^{* * *} \\
{[0.030]}\end{array}$ & $\begin{array}{c}-0.222^{* * *} \\
{[0.035]}\end{array}$ & $\begin{array}{c}-0.253^{* * *} \\
{[0.038]}\end{array}$ & $\begin{array}{c}-0.362^{* * *} \\
{[0.051]}\end{array}$ \\
\hline Fat & $\begin{array}{c}0.015 \\
{[0.060]}\end{array}$ & $\begin{array}{c}-0.133^{* * *} \\
{[0.043]}\end{array}$ & $\begin{array}{c}-0.187^{* * *} \\
{[0.035]}\end{array}$ & $\begin{array}{c}-0.251^{* * *} \\
{[0.035]}\end{array}$ & $\begin{array}{c}-0.304^{* * *} \\
{[0.037]}\end{array}$ & $\begin{array}{c}-0.348^{* * *} \\
{[0.036]}\end{array}$ & $\begin{array}{c}-0.391^{* * *} \\
{[0.037]}\end{array}$ & $\begin{array}{c}-0.459^{* * *} \\
{[0.047]}\end{array}$ & $\begin{array}{c}-0.464^{* * *} \\
{[0.051]}\end{array}$ \\
\hline Protein & $\begin{array}{c}0.005 \\
{[0.047]}\end{array}$ & $\begin{array}{c}-0.05 \\
{[0.033]}\end{array}$ & $\begin{array}{c}-0.117^{* * *} \\
{[0.033]}\end{array}$ & $\begin{array}{c}-0.172^{* * *} \\
{[0.032]}\end{array}$ & $\begin{array}{c}-0.229^{* * *} \\
{[0.033]}\end{array}$ & $\begin{array}{c}-0.280^{* * *} \\
{[0.036]}\end{array}$ & $\begin{array}{c}-0.404^{* * *} \\
{[0.051]}\end{array}$ & $\begin{array}{c}-0.669^{* * *} \\
{[0.092]}\end{array}$ & $\begin{array}{c}-2.422^{* * *} \\
{[0.763]}\end{array}$ \\
\hline Animal-source protein & $\begin{array}{c}-1.312^{* * * *} \\
{[0.388]}\end{array}$ & $\begin{array}{c}-0.633^{* * *} \\
{[0.155]}\end{array}$ & $\begin{array}{c}-0.614^{* * *} \\
{[0.115]}\end{array}$ & $\begin{array}{c}-0.586^{* * *} \\
{[0.101]}\end{array}$ & $\begin{array}{c}-0.505^{* * *} \\
{[0.092]}\end{array}$ & $\begin{array}{c}-0.456^{* * *} \\
{[0.081]}\end{array}$ & $\begin{array}{c}-0.479^{* * *} \\
{[0.074]}\end{array}$ & $\begin{array}{c}-0.412^{* * *} \\
{[0.075]}\end{array}$ & $\begin{array}{c}-0.587^{* * *} \\
{[0.082]}\end{array}$ \\
\hline Non-animal-source protein & $\begin{array}{c}0.046 \\
{[0.051]}\end{array}$ & $\begin{array}{c}-0.049 \\
{[0.033]}\end{array}$ & $\begin{array}{c}-0.098^{* * *} \\
{[0.031]}\end{array}$ & $\begin{array}{c}-0.142^{* * *} \\
{[0.031]}\end{array}$ & $\begin{array}{c}-0.211^{* * *} \\
{[0.033]}\end{array}$ & $\begin{array}{c}-0.259^{* * *} \\
{[0.037]}\end{array}$ & $\begin{array}{c}-0.359^{* * *} \\
{[0.047]}\end{array}$ & $\begin{array}{c}-0.562^{* * *} \\
{[0.090]}\end{array}$ & $\begin{array}{c}-2.686^{* * *} \\
{[0.823]}\end{array}$ \\
\hline
\end{tabular}

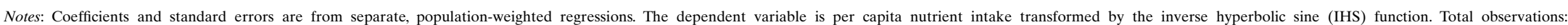
20,483. Standard errors are clustered bootstrap estimates. Asterisks ${ }^{*},{ }^{* *}$, and ${ }^{* * *}$ denote significance at the $10 \%, 5 \%$, and $1 \%$ levels, respectively. 
Table 6. Effects of Wheat Flour Price Increases on the Share of Calories from Non-staples

\begin{tabular}{ccccccccc}
\hline 10th & 20 th & 30th & 40th & 50th & 60th & 70th & 80th & 90th \\
\hline$-0.036^{* * *}$ & $-0.044^{* * *}$ & $-0.052^{* * *}$ & $-0.057^{* * *}$ & $-0.062^{* * *}$ & $-0.063^{* * *}$ & $-0.065^{* * *}$ & $-0.075^{* * *}$ & $-0.073^{* * *}$ \\
{$[0.009]$} & {$[0.009]$} & {$[0.010]$} & {$[0.010]$} & {$[0.010]$} & {$[0.011]$} & {$[0.012]$} & {$[0.015]$} & {$[0.017]$} \\
\hline
\end{tabular}

Notes: Coefficients and standard errors are from separate, population-weighted regressions with the dependent variable share of calories from non-staples. Non-staples include all non-grain foods. Total observations: 20,483. Standard errors are clustered bootstrap estimates. Asterisks $*$, $* *$ and *** denote significance at the $10 \%, 5 \%$, and $1 \%$ levels, respectively.

share of staples in their diets due to a decline in purchasing power. Households with higher initial shares of calories from non-staples make relatively larger adjustments than those with lower initial shares. These results are consistent with those of the food consumption score above; Afghan households across the distribution are getting relatively more of their calories from one food groupgrains-and thus the diversity of their diets declines.

\section{How Households Adapt}

To supplement our findings on the impact of the wheat flour price increases, we investigate the dietary adjustments (linked to specific food groups) that are responsible for the observed reductions in caloric intake and dietary diversity. ${ }^{38}$ To explain the calorie results, we examine changes in per capita calories from each of eight different food groups; to explain the dietary diversity results, we look at changes in calorie shares from these food groups. ${ }^{39}$ Given that some households exhibit zero values for some food groups, we again use the IHS transformation for the dependent variables as described above. We try to explain the behavior of subpopulations at the bottom $\left(10^{\text {th }}\right.$ to $30^{\text {th }}$ quantiles) and at the top ( $70^{\text {th }}$ to $90^{\text {th }}$ quantiles) of the calorie and dietary diversity distributions, that is, relatively low and relatively high ranges on each distribution. We

\footnotetext{
${ }^{38}$ We also investigated changes in the number of meals shared with guests; the results were inconclusive, with mixed signs and statistical significance. Given the cultural norms in Afghanistan regarding meal sharing and hospitality toward guests, such results are perhaps not surprising. The summary statistics show that households at the top of the food security distributions do share more meals with guests than households at the bottom of the distributions. However, increases in the price of wheat flour do not affect meal-sharing in a systematic way.

${ }^{39}$ We use per capita caloric intakes from each food group to explain the calorie results because they link directly to total per capita caloric intake for the household. We use calorie shares per food group to explain the diversity results because, in part, the shares incorporate the tradeoff between various food groups diversity is related to the number of food groups consumed, as well as the frequency with which they are consumed.
}

Table 7a. Changes in Per Capita Calories for Subpopulations of Households

\begin{tabular}{|c|c|c|}
\hline \multirow[b]{2}{*}{ Food group: } & \multicolumn{2}{|c|}{ Subsample } \\
\hline & $\begin{array}{c}\text { 10th - 30th } \\
\text { quantiles of } \\
\text { calorie } \\
\text { distribution }\end{array}$ & $\begin{array}{c}\text { 70th }-90 \text { th } \\
\text { quantiles of } \\
\text { calorie } \\
\text { distribution }\end{array}$ \\
\hline \multirow[t]{2}{*}{ Grains } & $0.095^{* * *}$ & $0.153^{* * *}$ \\
\hline & {$[0.021]$} & {$[0.040]$} \\
\hline \multirow[t]{2}{*}{ Pulses } & 0.138 & -0.408 \\
\hline & [0.290] & [0.317] \\
\hline \multirow[t]{2}{*}{ Vegetables } & -0.036 & $-0.341^{* *}$ \\
\hline & {$[0.114]$} & [0.136] \\
\hline \multirow[t]{2}{*}{ Fruit } & $-1.418^{* * *}$ & $-2.248^{* * *}$ \\
\hline & {$[0.324]$} & [0.387] \\
\hline \multirow[t]{2}{*}{ Meat and fish } & $-0.897^{* * *}$ & $-0.839^{* * *}$ \\
\hline & {$[0.261]$} & {$[0.263]$} \\
\hline \multirow[t]{2}{*}{ Dairy } & 0.108 & $-1.102^{* * *}$ \\
\hline & [0.264] & [0.307] \\
\hline \multirow[t]{2}{*}{ Sugars } & -0.101 & $-0.775^{* * *}$ \\
\hline & [0.185] & {$[0.228]$} \\
\hline \multirow[t]{2}{*}{ Oil and fat } & -0.047 & $-0.390^{* * *}$ \\
\hline & [0.139] & [0.142] \\
\hline
\end{tabular}

Notes: Coefficients and standard errors are from separate, populationweighted OLS regressions. The dependent variable is the per capita calories for each food group, transformed by the inverse hyperbolic sine (IHS) function to handle zeros. Total observations: 20,483. Standard errors are corrected for clustering and stratification. Asterisks *, **, and *** denote significance at the $10 \%, 5 \%$, and $1 \%$ levels, respectively.

chose these ranges to draw a balanced (and sufficiently large) sample around the $20^{\text {th }}$ and $80^{\text {th }}$ quantiles. ${ }^{40}$ We use OLS methods to estimate these changes since we are interested in the average price effects for each subpopulation.

Table $7 \mathrm{a}$ presents estimated changes in per capita calories for each food group for subpopulations at low and high points of the calorie distribution range. Recall that the negative UQR price effects are larger

\footnotetext{
${ }^{40}$ We recognize that systematically subsampling on the dependent variables inherently introduces sample-selection bias and, in part, this is a motivation for our primary approach of examining effects at different parts of the distribution rather than for different sub-samples of the dependent variable. Nonetheless, to provide a more detailed description, even if potentially biased, we also present findings from the sub-sample approach.
} 
Table 7b. Changes in Calorie Shares for Subpopulations of Households

\begin{tabular}{lcc}
\hline & \multicolumn{2}{c}{ Subsample } \\
& 10th - 30th & 70th -90 th \\
& quantiles of & quantiles of \\
dietary diversity & dietary diversity \\
Food group: & distribution & distribution \\
\hline Grains & $0.045^{* * *}$ & $0.028^{* * *}$ \\
Pulses & {$[0.011]$} & {$[0.011]$} \\
& -0.002 & -0.006 \\
Vegetables & {$[0.003]$} & {$[0.005]$} \\
Fruit & $-0.006^{* * *}$ & -0.001 \\
& {$[0.002]$} & {$[0.002]$} \\
Meat and fish & $-0.008^{* * *}$ & $-0.014^{* * *}$ \\
& {$[0.003]$} & {$[0.005]$} \\
Dairy & -0.001 & 0.003 \\
& {$[0.003]$} & {$[0.005]$} \\
Sugars & 0.005 & -0.009 \\
& {$[0.005]$} & {$[0.008]$} \\
Oil and fat & $-0.007^{* *}$ & 0.003 \\
& {$[0.003]$} & {$[0.003]$} \\
& $-0.037^{* * *}$ & -0.005 \\
& {$[0.008]$} & {$[0.007]$} \\
\hline
\end{tabular}

Notes: Coefficients and standard errors are from separate, populationweighted OLS regressions. The dependent variable is the calorie shares from each food group, transformed by the inverse hyperbolic sine (IHS) function to handle zeros. Total observations: 20,483. Standard errors are corrected for clustering and stratification. Asterisks *, ${ }^{* *}$, and *** denote significance at the $10 \%, 5 \%$, and $1 \%$ levels, respectively.

in magnitude as we move higher on the distribution. For the richer (in terms of caloric intake) households, we observe a general scaling back across all food groups (though the coefficient on pulses is not significant) in favor of grains. And while the price of wheat increased, it continued to be one of the cheaper sources of calories. For the caloriepoor households, the shift in the composition of food consumption is less balanced across the food types. These households focus all of their change on reducing the calories from the most expensive of sources, which is meat/fish and fruit. The former is a very expensive source of calories, and there is evidence that the latter can be considered a luxury good in developing countries (Zhang and Wang 2011).

Table $7 \mathrm{~b}$ presents estimated changes in calorie shares for each food group for subpopulations at low and high points of the dietary diversity distribution. (Recall that the UQR price effects are significant and negative across the distribution, with slightly larger effects seen for those at the bottom). The results do not shed much light on the behavior of the richer (in terms of diversity)

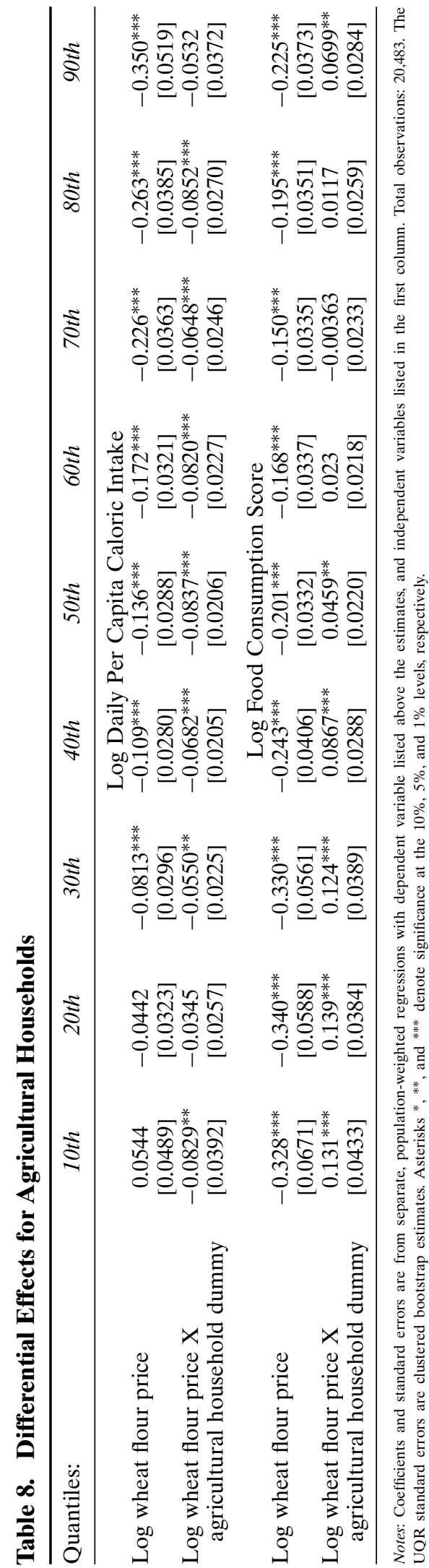


households. They reduce their calorie share from fruit and increase the share from grains, but for the most part these households do not seem to be making large adjustments in their calorie shares. In contrast, for the poorer households we observe a stronger shift in calorie shares toward grains, with declines in calorie shares from several food groups (vegetables, fruit, sugars, and oil/fat). Since the diets of these households are not very diverse, reductions in calorie shares coming from non-grain groups could have large effects on measured dietary diversity. Furthermore, these households are consuming very small quantities of food, so even small reductions are notable and are indicative of a movement into a less diverse diet that focuses on staples.

\section{Differential Effects for Agricultural Households}

In this section we present differential effects for agricultural households (those who own or operate agricultural land). During periods of high food prices, these households may not be as harmed as other households because they are able to produce their own food and are less dependent on the market. Furthermore, if they produce more food than they consume (i.e., they are net sellers), they can sell the food on the market and profit from the high prices. Ideally, we would like to identify the net sellers of wheat, but unfortunately the NRVA data do not allow us to do so. Therefore, we use a dummy for agricultural households as a broad proxy and include it as an interaction with the log of wheat flour prices to capture potentially differential effects.

Both non-agricultural and agricultural households higher on the calorie distribution range experience larger declines (table 8). Most agricultural households experience a larger decline in calories than their non-agricultural counterparts (though the differential effects for households at the $20^{\text {th }}$ and $90^{\text {th }}$ quantiles are not significantly different). At the bottom end of the distribution, non-agricultural households do not experience a decline, but agricultural households experience a small decline. In terms of dietary diversity, non-agricultural households at the bottom of the distribution are the most affected. Agricultural households at the bottom half of the diversity distribution and at the $90^{\text {th }}$ quantile are able to buffer the impact of the price increases better than their counterparts. Through home food production, agricultural households may have greater access to an assortment of foods, which would make it relatively easier for them to maintain a more diverse diet.

An important caveat to these results is that not all agricultural households are net sellers of wheat, ${ }^{41}$ and thus these results may not capture the true differential effects for net sellers. Furthermore, even if households had access to agricultural land, the severe drought of 2008 may have limited or destroyed their yields. Thus, during the survey year there may not have been many net sellers of wheat in Afghanistan. ${ }^{42}$

\section{Caveats}

In interpreting the results, certain limitations of the data-particularly of household food consumption data-must be acknowledged. The NRVA survey uses a 7-day recall method with 91 food items to collect food consumption data. With such a method, there is the potential of measurement error associated with recall, waste, and meals away from home.

Recall bias stems from memory lapses of the respondent when recalling food consumed over long periods of time. The World Food Programme recommends using a 7day recall method to capture regularities in food consumption patterns and the range of foods consumed while minimizing recall bias (World Food Programme 2008). Using data from a field experiment in Tanzania, Beegle et al. (2012) find that mean consumption and inequality measures from 7-day recall data were closest to the benchmark data (based on food diaries). Further, Drewnowski et al. (1997) argue that it is best for dietary diversity measures to be constructed from recall data that are longer than 3 days and shorter than 10 days. Recall periods of 1 to 3 days did not adequately represent the variety of foods consumed by households; recall periods of 10 to 13 days did not produce observable differences in the dietary diversity measures.

\footnotetext{
41 Given that Afghanistan imports an average of $20 \%$ of its consumed wheat flour and has insufficient storage and milling capacity to meet consumption needs (Haroun 2010), it strikes us as a reasonable view that identifying a household as an agricultural household may not be too informative as to whether they are growing more wheat than they are purchasing.

42 The drought was the worst in the ten preceding years, with losses reported on both rainfed and irrigated wheat crops (Foreign Agricultural Service 2008).
} 
Household consumption data do not typically account for food wastage, and thus estimates of food intake may be larger than actual values. We assume that in a poor country like Afghanistan, wastage is relatively small and not a significant source of bias. Generally, in low income countries like Afghanistan, much less food is wasted at the consumer level than at early and middle stages of the food supply chain (FAO 2011). A potentially more challenging concern is if wastage is correlated with price volatility. If the amount of food wasted is negatively correlated with food prices (as might be expected), then the coefficients on the price of wheat flour in the calorie regressions will have positive biases. ${ }^{43}$ Our maintained assumption, however, is that wastage is low, and any potential bias is small.

A third challenge is accounting for food consumption and expenditure for meals away from home. The survey asks how many meals were eaten outside of the home by household members over the previous 7 days, and the value of food and drinks consumed outside the home over the previous 30 days. However, there is no information on what food is consumed outside the household. ${ }^{44}$ Therefore, we do not include any calories from food away from home in the caloric intake calculation, nor does food away from home impact the food consumption score. These measures may not accurately capture all food consumed by members of the household. However, without detailed food diaries it is difficult to obtain sufficient information. Food away from home constitutes about 2\% of total food expenditure, on average; it is less than $0.5 \%$ for the poorest $20 \%$ of the population, and about $4 \%$ for the richest $20 \%$ of the population.

\section{Conclusion}

We use the case of Afghanistan to examine the impact of increases in staple food prices

\footnotetext{
${ }^{43}$ The sign of the bias is determined by the product of the correlation coefficients of (i) food waste and wheat flour prices, and (ii) food waste and caloric intake. If both correlation coefficients are negative, then their product, and thus the sign of the bias, is positive.

${ }_{44}$ We use the questions on meals eaten outside the home and the value of food and drinks consumed to calculate average expenditure on food away from home for each household, which is included in the total value of food consumption.
}

on household food security. Unique household and price data collected before and during the 2007-2008 food price crisis provide the rare opportunity to precisely measure the behavioral responses of households. We examine several measures related to food security: caloric intake, dietary diversity, the share of calories from non-staples, and nutrient intakes. We use the unconditional quantile regression estimator to examine the marginal effect of a change in wheat prices at deciles of the unconditioned distribution of each food security measure.

The key findings of our analysis illustrate the value of distribution-sensitive analysis. We find large differences in the behavioral responses of a household based on its location on the distribution. Households at the bottom of the caloric intake distribution make very small to no reductions in caloric intake. Households living near caloricsubsistence levels are vulnerable to many adverse health effects, and need to find ways to absorb the price shock without further reducing calories. These vulnerable households may have limited options to buffer food price shocks. While we know that food purchases make up the vast majority of their total consumption, they cannot easily scale back on calories. On the other hand, we find that households at the top of the distribution do experience significant declines in caloric intake. These households scale back on calories from most major food groups, substituting toward grains instead.

The wheat flour price increases also led to reductions in dietary diversity, with slightly larger reductions observed for those at the bottom of the diversity distribution than those at the top. Those at the bottom shift their shares of calories out of many core food groups (vegetables, fruit, sugars, and oil/fat) into grains. Such changes indicate a serious decline in diversity for those who already enjoy little diversity in their diets.

The key policy implication from this work is linked to the monitoring of vulnerability rather than policy design. In their guidelines for assessing household-level food security, the Food and Agriculture Organization of the United Nations and the World Food Programme (2009) suggest examining a food consumption score, food expenditure estimates, or caloric intake. The guidelines are written to provide assistance to on-theground teams who assess whether action needs to be taken to address potential food 
insecurity problems. The guidelines are intended to be practical responses to datapoor environments, suggesting that either the food consumption score or calorie data can be informative, but our findings are less optimistic about the value of calories as an informative proxy. Rather, our findings indicate that for vulnerable populations calories are relatively insensitive (at least in the shortrun) to adverse shocks, while dietary diversity is relatively more sensitive to shocks. This is consistent with Ruel (2003), who finds that dietary changes can be detected before changes in micronutrient status. The key point is that policies designed to be triggered by a decline in calories to levels below subsistence needs will fail to detect the onset of food insecurity in a timely way. Given that the food consumption score can be collected much more quickly than calorie data, the findings provide strong support for the value of this measure. ${ }^{45}$

It is important to note that the findings do not argue against the provision of calories through the release of staple-crop reserves. Even though we find that those consuming at the margin of basic caloric needs do not reduce their calories in the presence of an adverse shock, this does not mean that the provision of calories in some form will not help them. Receiving a staple crop could very well be a useful transfer, allowing the household to either supplement the staple crop with a more diverse diet or to purchase needed nonfood items. The standard response to food crises, which is to increase the distribution of grains, is useful because it essentially increases the ability of a household to consume a more diverse diet. The key findings of this analysis emphasize the importance of enhancing the standard policy response with interventions that directly address dietary diversity through micronutrient interventions such as fortification of grains or nutrient supplementation.

\footnotetext{
45 Another aspect of this finding is to shed some light on the costs and benefits of collecting data on diversity and calories. A relatively common view is that there is a tradeoff between measures such as the food consumption score and calorie measures. Calorie data collection is time-consuming, but presumed to be a better indicator of food security, while data for a food consumption score is relatively easier to collect, but is a cruder, less informative measure. The findings from our analysis suggest that for the purposes of measuring the onset of food insecurity, this view is misguided.
}

In terms of methodological implications, the analysis also shows that a quantile estimator (or any estimator that allows marginal effects to vary across the distribution) reveals important information about the behavioral responses of those who are most vulnerable. For example, the significant differences in price responses for those at the top and the bottom of the caloric intake distribution suggest that households employ different coping mechanisms in the face of food price increases; those wishing to target vulnerable households may be interested in knowing the unique set of tradeoffs that these households face.

Finally, this article has implications for data collection. Household survey consumption modules often include questions on the quantity of or expenditure on food items consumed, but not on the frequency of consumption. Given the low cost of adding such questions, it may be beneficial to consider augmenting household surveys, particularly for populations that are vulnerable to food insecurity. Measures of dietary diversity are useful tools when detailed food journals or anthropometric data are not available. Ruel (2003) discusses some of the benefits and costs of indicators of dietary diversity. Alexander and Thomson (1992) discuss the importance of collecting frequency data in addition to quantity intake data. The authors demonstrate that both the quantity and frequency of food intake are important determinants of diet-induced diseases, and they argue that looking solely at quantity data could be misleading. Our findings are consistent with this view.

\section{References}

Alexander, C.J., and F.J. Thomson. 1992. The Threshold Effect: Consequences of Change in the Frequency of Food Intake in the Presence of a Functional Threshold. Medical Hypotheses 39 (3): 302-308.

Anríquez, G., S. Daidone, and E. Mane. 2013. Rising Food Prices and Undernourishment: A Cross-country Inquiry. Food Policy 38 (C): 190-202.

Arimond, M., and M.T. Ruel. 2004. Dietary Diversity Is Associated with Child Nutritional Status: Evidence from 11 Demographic and Health Surveys. The Journal of Nutrition 134 (10): 2579-2585. 
Balagtas, J.V., H. Bhandari, S. Mohanty, E. Cabrera, and M. Hossain. 2012. Impact of a Commodity Price Spike on Poverty Dynamics: Evidence from a Panel of Rural Households in Bangladesh. Paper presented at Australian Agricultural and Resource Economics Society, Fremantle.

Beegle, K., J. De Weerdt, J. Friedman, and J. Gibson. 2012. Methods of Household Consumption Measurement through Surveys: Experimental Results from Tanzania. Journal of Development Economics 98 (1): 3-18.

Bibi, S., J. Cockburn, M. Coulibaly, and L. Tiberti. 2009. The Impact of the Increase in Food Prices on Child Poverty and the Policy Response in Mali. United Nations Children's Fund Innocenti Research Centre Working Paper.

Block, S.A., L. Kiess, P. Webb, S. Kosen, R. Moench-Pfanner, M.W. Bloem, and C. Peter Timmer. 2004. Macro Shocks and Micro Outcomes: Child Nutrition during Indonesia's Crisis. Economics \& Human Biology 2 (1): 21-44.

Brinkman, H.-J., S. de Pee, I. Sanogo, L. Subran, and M.W. Bloem. 2010. High Food Prices and the Global Financial Crisis Have Reduced Access to Nutritious Food and Worsened Nutritional Status and Health. The Journal of Nutrition 140 (1): 153S-161S.

Buchinsky, M. 1994. Changes in the U.S. Wage Structure 1963-1987: Application of Quantile Regression. Econometrica 62 (2): 405-458.

Burbidge, J.B., L. Magee, and A.L. Robb. 1988. Alternative Transformations to Handle Extreme Values of the Dependent Variable. Journal of the American Statistical Association 83 (401): 123-127.

Buse, R.C., and L.E. Salathe. 1978. Adult Equivalent Scales: An Alternative Approach. American Journal of Agricultural Economics 60 (3): 460-468.

Carter, M.R., and T.J. Lybbert. 2012. Consumption versus Asset Smoothing: Testing the Implications of Poverty Trap Theory in Burkina Faso. Journal of Development Economics 99 (2): 255-264.

Chabot, P., and P.A. Dorosh. 2007. Wheat markets, food aid and food security in Afghanistan. Food Policy 32 (3): 334-353.

Chamberlain, G. 1994. Quantile Regression, Censoring, and the Structure of Wages, In Advances in Econometrics Sixth World
Congress Volume 1, ed. C. Sims, 171210. Cambridge: Cambridge University Press.

Cutler, D., and L. Katz. 1992. Rising Inequality? Changes in the Distribution of Income and Consumption in the 1980s. American Economic Review 82 (2): 546-551.

D'Souza, A., and D. Jolliffe. 2012. Rising Food Prices and Coping Strategies: Household-level Evidence from Afghanistan. Journal of Development Studies 48(2): 282-299.

de Hoyos, R.E., and D. Medvedev. 2011. Poverty Effects of Higher Food Prices: A Global Perspective. Review of Development Economics 15 (3): 387-402.

Deaton, A., and V. Kozel. 2005. Data and Dogma: The Great Indian Poverty Debate. The World Bank Research Observer 20 (2): 177-199.

Diagana, B., F. Akindès, K. Savadogo, T. Reardon, and J. Staatz. 1999. Effects of the CFA franc devaluation on urban food consumption in West Africa: overview and cross-country comparisons. Food Policy 24 (5): 465-478.

Drewnowski, A., S.A. Renderson, A. Driscoll, and B.J. Rolls. 1997. The Dietary Variety Score: Assessing Diet Quality in Healthy Young and Older Adults. Journal of the American Dietetic Association 97 (3): 266-271.

Dufour, C., and A. Borrel. 2007. Towards a public nutrition response in Afghanistan: evolutions in nutritional assessment and response, In Reconstructing Agriculture in Afghanistan, ed. A. Pain and J. Sutton, 93-118. Rome: United Nations Food and Agriculture Organization and Practical Action Publishing.

Ecker, O., and M. Qaim. 2011. Analyzing Nutritional Impacts of Policies: An Empirical Study for Malawi. World Development 39 (3): 412-428.

Fanzo, J., and P. Pronyk. 2010. An evaluation of progress toward the Millennium Development Goal One Hunger target: a country-level, food and nutrition security perspective. Rome: World Food Programme.

Firpo, S., N. Fortin, and T. Lemieux. 2009. Supplement to Unconditional Quantile Regressions: Estimation and Testing. Econometrica 77 (3): 953-973. - 2009. Unconditional Quantile Regression. Econometrica 77 (3): 953-973. 
Friedman, J., S.Y. Hong, and X. Hou. 2011. The Impact of the Food Price Crisis on Consumption and Caloric Availability in Pakistan: Evidence from Repeated Cross-sectional and Panel Data. World Bank Health, Nutrition, and Population Discussion Paper. Washington, D.C.

Hampel, F., E. Ronchetti, P. Rousseeuw, and W. Stahel. 1988. Robust Statistics: The Approach Based on Influence Functions. New York: Wiley.

Haroun, M. 2010. Food Crisis and its Impact on Afghanistan's National Security, in Managing Food Price Inflation in South Asia, ed. S. Ahmed and H.G.P. Jansen, 145-170. Dhaka: The University Press Limited.

International Fund for Agricultural Development. 2008. Soaring food prices and the rural poor: feedback from the field. Rome.

Islamic Republic of Afghanistan, Central Statistics Organization, and World Bank Economic Policy and Poverty Sector. 2011. Setting the Official Poverty Line for Afghanistan. Kabul.

Islamic Republic of Afghanistan, Ministry of Economy, and the World Bank Economic Policy and Poverty Sector. 2010. Poverty Status in Afghanistan: A Profile Based on the National Risk and Vulnerability Assessment (NRVA) 2007/08. July.

Ivanic, M., and W. Martin. 2008. Implications of Higher Global Food Prices for Poverty in Low-Income Countries. World Bank Policy Research Working Paper 4594. Washington, D.C.

Jacobs, P.T. 2010. Household Food Insecurity, Rapid Food Price Inflation and the Economic Downturn. Paper presented at Agricultural Economists Association of South Africa Annual Conference. Cape Town.

Jensen, R.T., and N.H. Miller. 2008. Giffen Behavior and Subsistence Consumption. The American Economic Review 98 (4): 1553-1577.

- 2008. The impact of food price increases on caloric intake in China. Agricultural Economics 39: 465-476.

- 2010. A Revealed Preference Approach to Measuring Hunger and Undernutrition. NBER Working Paper 16555.

Johnson, N.L. 1949. Systems of Frequency Curves Generated by Methods of Translation. Biometrika 36 (1/2): 149-176.
Kish, L. 1965. Survey Sampling. New York: Wiley.

Klotz, C., S. de Pee, A. Thorne-Lyman, K. Kraemer, and M.W. Bloem. 2008. Nutrition in the Perfect Storm: Why Micronutrient Malnutrition will be a Widespread Health Consequence of High Food Prices. Sight and Life Magazine (2).

Koenker, R., and G. Bassett, Jr. 1978. Regression Quantiles. Econometrica 46 (1): 33-50.

- 1982. Robust Tests for Heteroscedasticity Based on Regression Quantiles. Econometrica 50 (1): 43-61.

Layton, D.F. 2001. Alternative Approaches for Modeling Concave Willingness to Pay Functions in Conjoint Valuation. American Journal of Agricultural Economics 83 (5): 1314-1320.

Martin-Prevel, Y., F. Delpeuch, P. Traissac, J.-P. Massamba, G. Adoua-Oyila, K. Coudert, and S. Treche. 2000. Deterioration in the nutritional status of young children and their mothers in Brazzaville, Congo, following the 1994 devaluation of the CFA franc. International Journal of Public Health. 78 (1): 108-118.

Micronutrient Initiative and United Nations Children's Fund. Global Report 2009: Investing in the future: A united call to action on vitamin and mineral deficiencies. Ontario.

Minot, N., and R. Dewina. 2013. Impact of Food Price Changes on Household Welfare in Ghana. IFPRI Discussion Paper 01245. Washington, D.C.

National Planning Commission, and Central Bureau of Statistics. 2013. Nepal Thematic Report on Food Security and Nutrition. Government of Nepal. Kathmandu.

Ramakrishnan, U. 2002. Prevalence of Micronutrient Malnutrition Worldwide. Nutrition Reviews 60: S46-S52.

Robles, M., and M. Torero. 2010. Understanding the Impact of High Food Prices in Latin America. Economía 10 (2): 117-164.

Ruel, M.T. 2003. Operationalizing Dietary Diversity: A Review of Measurement Issues and Research Priorities. The Journal of Nutrition 133 (11): 3911S-3926S.

Ruel, M.T., J.L. Garrett, C. Hawkes, and M.J. Cohen. 2010. The Food, Fuel, and Financial Crises Affect the Urban and Rural Poor Disproportionately: A Review of 
the Evidence. The Journal of Nutrition 140 (1): 170S-176S.

Sanogo, I. 2009. The global food price crisis and household hunger: a review of recent food security assessments. Humanitarian Exchange (42): 8-11.

Sari, M., S. de Pee, M.W. Bloem, K. Sun, A.L. Thorne-Lyman, R. Moench-Pfanner, N. Akhter, K. Kraemer, and R.D. Semba. 2010. Higher Household Expenditure on Animal-source and Nongrain Foods Lowers the Risk of Stunting among Children 0-59 Months Old in Indonesia: Implications of Rising Food Prices. The Journal of Nutrition 140 (1): 195S-200S.

Schnepf, R., and J. Richardson. 2013. Consumers and Food Price Inflation. Congressional Research Service. Report R40545. Washington, D.C.

Simler, K.R. 2010. The Short-Term Impact of Higher Food Prices on Poverty in Uganda. World Bank Policy Research Working Paper 5210. Washington, D.C.

Steyn, N.P., J.H. Nel, G. Nantel, G. Kennedy, and D. Labadarios. 2006. Food variety and dietary diversity scores in children: are they good indicators of dietary adequacy? Public Health Nutrition 9 (5): 644-650.

Sulaiman, M., M. Parveen, and N.C. Das. Impact of the Food Price Hike on Nutritional Status of Women and Children. BRAC Reseach and Evaluation Division. Monograph Series No. 38. Dhaka.

Tiwari, S., and H. Zaman. 2010. The Impact of Economic Shocks on Global Undernourishment. World Bank Policy Research Working Paper Series 5215. Washington, D.C.

Torlesse, H., L. Kiess, and M.W. Bloem. 2003. Association of Household Rice Expenditure with Child Nutritional Status Indicates a Role for Macroeconomic Food Policy in Combating Malnutrition. The Journal of Nutrition 133: 1320-1325.

U1 Haq, Z., H. Nazli, and K. Meilke. 2008. Implications of high food prices for poverty in Pakistan. Agricultural Economics 39: 477-484.

United Nations Children's Fund. 2009. The State of the World's Children 2009: Maternal and Newborn Health. New York.

- 2009. Tracking Progress on Child and Maternal Nutrition: a survival and development priority. New York.
United Nations, Food and Agriculture Organization. 2012. FAOSTAT database. Rome.

2012. Integrating Food Security Information in National Statistical Systems. Rome.

2011. Global Food Losses and Food Waste. Rome.

2008. The State of Food Security in the World 2008: High Food Prices and Food Security - Threats and Opportunities. Rome.

2006. Food Security. Rome.

United Nations, Food and Agriculture Organization, and World Food Programme. 2012. FAO/WFP Joint Guidelines for Crop and Food Security Assessment Missions (CFSAMs). Rome.

United States Department of Agriculture, Foreign Agricultural Service. 2008. Afghanistan: Severe Drought Causes Major Decline in 2008/09 Wheat Production. August 12. Washington, D.C.

United States Department of Agriculture, Foreign Agricultural Service. 2008. Commodity Intelligence Report. August 12.

Weismann, D., L. Bassett, T. Benson, and J. Hoddinott. 2009. Validation of the World Food Programme's Food Consumption Score and Alternative Indicators of Household Food Security. IFPRI Discussion Paper 00870. June. Washington, D.C.

Wodon, Q.T., C. Tsimpo, P. Backiny-Yetna, G. Joseph, F. Adoho, and H. Coulombe. 2008. Potential impact of higher food prices on poverty: summary estimates for a dozen west and central African countries. World Bank Policy Research Working Paper Series 4745. Washington, D.C.

World Bank, and International Monetary Fund. Global Monitoring Report 2012: Food Prices, Nutrition and the Millennium Development Goals. Washington, D.C.

World Food Programme. 2008. Food consumption analysis: Calculation and use of the food consumption score in food security analysis. Rome.

Zhang, Q. and Y. Wang. 2011. Fruit and Vegetable Prices, Dietary Intakes and Income: Potential Cost versus Benefit. In Nutrients, Dietary Supplements, and Nutriceuticals, ed. J.K. Gerald, R.R. Watson, and V.R. Preedy. 63-73. New York: Humana Press. 